\title{
Intranasal Corticosteroids: Topical Potency, Systemic Activity and Therapeutic Index
}

\author{
Peter T Daley-Yates' \\ Désirée Larenas- \\ Linnemann (iD) ${ }^{2}$ \\ Chaitanya Bhargave ${ }^{3}$ \\ Manish Verma ${ }^{3}$ \\ 'Clinical Pharmacology and Experimental \\ Medicine, GlaxoSmithKline plc., Research \\ and Development, Uxbridge, UK; \\ ${ }^{2}$ Center of Excellence in Asthma and \\ Allergy, Médica Sur Clinical Foundation \\ and Hospital, México City, Mexico; \\ ${ }^{3}$ Respiratory and Allergy, \\ GlaxoSmithKline plc., Mumbai, India
}

Correspondence: Peter T Daley-Yates Clinical Pharmacology and Experimental Medicine, GlaxoSmithKline plc., Research and Development, Uxbridge, UK

Tel +44 2089902460

Fax +44 208990350

Email Peter.T.Daley-Yates@gsk.com

\begin{abstract}
Intranasal corticosteroid (INCS) therapy is the preferred treatment option for allergic rhinitis (AR). Although all INCSs for the treatment of AR are considered safe and effective, differences in potency, molecular structure features and physicochemical and pharmacokinetic properties could result in differences in clinical efficacy and safety. Higher glucocorticoid receptor (GR) binding affinity of INCS is associated with higher lipophilicity, nasal tissue retention and topical potency. Higher topical potency is also accompanied by low oral bioavailability and high systemic clearance conferring low systemic exposure, reduced potential for systemic adverse effects and an improved therapeutic index. It has been shown that adverse events related to systemic exposure of INCSs in children are low. Although INCSs mostly produce low systemic effects, use of an INCS with low systemic exposure in patients on multiple corticosteroid (CS) therapies could help reduce the total systemic burden of CS therapy. Despite differences in topical potency, physicochemical and pharmacokinetic properties between INCSs, clinical studies of INCSs in the treatment of AR generally show no clinically important differences between these compounds, and poor correlation between INCS topical potency and clinical response. However, the lack of head-to-head comparisons of INCSs in clinical studies conducted in more severe AR patients should be noted. This narrative review provides an assessment of the therapeutic relevance of topical potency and the physicochemical and pharmacokinetic properties of INCSs and describes for the first time the relationship between topical potency and therapeutic index using pharmacological features of INCSs. It concludes that higher GR binding affinity and topical potency can potentially improve the therapeutic index of an INCS. Therefore, both efficacy and systemic exposure profiles should be considered when comparing INCS regimens in terms of therapeutic equivalence, to aid clinical decision-making and avoid the assumption that all INCS formulations are the same when considering treatment options.
\end{abstract}

Keywords: corticosteroid, intranasal, topical potency, rhinitis therapeutic index

\section{Introduction}

Intranasal corticosteroid (INCS) therapy is the preferred treatment option for allergic rhinitis (AR). ${ }^{1-4}$ As many patients with AR also have asthma, INCSs are often used concurrently with standard maintenance therapy for asthma such as inhaled corticosteroids (ICS). ${ }^{5,6}$ A range of INCS treatments are currently available in Europe and the US for AR treatment, including first-generation $\mathrm{INCSs}^{7-9}$ triamcinolone acetonide (TAA), flunisolide (FLU) (US only), budesonide (BUD), dexamethasone (DEX), beclomethasone dipropionate (BDP), and secondgeneration $^{7,8}$ INCS ciclesonide (CIC) (US only), fluticasone propionate (FP), mometasone furoate $(\mathrm{MF})$ and fluticasone furoate $(\mathrm{FF})$. These treatments are 
available as pump sprays or aerosol metered-dose inhalers (MDI); an aqueous nasal spray (ANS) pump is the most commonly used device. ${ }^{10,11}$ All INCSs prescribed for the treatment of AR are considered safe and effective, however, these molecules have structural differences that influence their glucocorticoid receptor (GR) binding affinity and topical anti-inflammatory potency. These structural differences also alter the physicochemical properties such as solubility, lipophilicity and permeability, which in turn influence the pharmacokinetic properties and thereby the systemic activity and therapeutic index. ${ }^{12,13}$ Consequently, variations in molecular structure and their subsequent effects on INCS properties should be considered in AR management to ensure that patients receive the most suitable medication for their needs.

In keeping with the potential differences between INCSs described above, studies comparing potential adverse events associated with INCS use should not be conducted in isolation from clinical efficacy analysis, and both efficacy and safety should be considered when classifying INCS regimens in terms of therapeutic equivalence. Only one publication to date has explored the relationship between INCS topical potency and therapeutic index using clinical endpoints. In 2011, Schafer et $\mathrm{al}^{14}$ conducted a systematic literature review (1996 to June 2009), identifying 84 relevant placebo-controlled randomized trials and observational studies reporting on INCSs (BUD, FP, FF, MF, TAA and BDP) as treatments for AR. Data on three efficacy outcomes (nasal symptoms, ocular symptoms, and global assessment) and three safety outcomes (epistaxis, growth, and systemic ocular effects) from identified studies were collected and analyzed. The therapeutic index for each INCS was presented as the ratio of summation scores for efficacy and safety, which were calculated using clinical endpoint scores. ${ }^{14}$ Although there were differences in the therapeutic indexes between INCS treatments, it was difficult to assess the clinical relevance of these differences. Thus, to guide clinical decision-making, there is a need for a more robust comparison of different INCS therapies that incorporates pharmacological principles, rather than focusing only on clinical endpoints that lack sensitivity for differentiation, particularly as there is a lack of robust clinical studies that directly compare two or more INCSs in the same study.

INCSs are considered to have similar efficacy and safety profiles. Therefore, differences in sensory attributes of the formulation (such as taste, smell, aftertaste or throat rundown), perception of safety during pregnancy, and cost are all factors underlying patient preference and adherence to therapy. ${ }^{15}$ Additionally, some clinicians are still reluctant to prescribe INCS because of concerns of systemic effects, especially on growth in children. ${ }^{4}$ This narrative review aims to guide clinical decision-making and help specialists make more informed treatment decisions through better characterized efficacy/safety profiles of different INCS treatments. It also aims to provide an assessment of the therapeutic relevance of topical potency and physicochemical and pharmacokinetic properties of INCSs and describes for the first time the relationship between topical potency and therapeutic index based on molecular and pharmacological features of INCSs.

\section{Topical Potency}

Over time, newer INCS molecules such as FP, MF and FF have been introduced, with increased GR binding affinity, GR selectivity, greater uptake and retention in nasal tissue, and reduced systemic bioavailability compared to older INCS molecules, such as DEX, BDP and BUD., ${ }^{9,13}$ The relative GR binding affinity of INCSs varies 30 -fold from DEX (100) to FF (2989) (Table 1). There is a correlation between the relative GR binding affinity of INCSs and their established therapeutic doses (Figure 1), which suggests GR binding affinity is a key factor driving topical potency, thereby leading to physicochemical and pharmacokinetic changes that can reduce systemic exposure. ${ }^{12}$ However, topical potency of an INCS likely depends not only on the GR binding affinity but also on the efficiency of nasal drug delivery and the resulting uptake and retention in nasal tissue. While increased topical potency at intranasal sites can potentially improve efficacy, systemic absorption of INCSs could pose safety risks as INCSs could interact with GRs found throughout the body. ${ }^{1}$ Therefore, INCSs with increased topical potency are not considered to offer a therapeutic advantage over INCSs with less topical potency. ${ }^{1,12}$ A review published in 2005 suggested that there is no evidence that INCS doses greater than the recommended maximum increase efficacy, ${ }^{16}$ which is consistent with various reviews ${ }^{1,9,15}$ and AR management guidelines ${ }^{3}$ that have demonstrated INCS treatments are widely regarded as therapeutically similar in the clinical setting.

The molecular structure changes that increase the GR binding affinity and selectivity of synthetic corticosteroids also alter their physicochemical properties, notably their lipophilicity ${ }^{12}$ (Table 1). The lipophilicity of corticosteroids (CS) has been shown to be highly correlated with GR affinity, 
Table I INCS Physicochemical, Pharmacokinetic and Pharmacological Characteristics

\begin{tabular}{|c|c|c|c|c|c|c|c|c|c|}
\hline INCS $^{a}$ & RRA $^{b}$ & $\log P^{c}$ & $\begin{array}{l}\text { Therapeutic } \\
\text { Dose }^{\mathrm{d}}, \mu \mathrm{g} / \\
\text { day }\end{array}$ & $\begin{array}{l}\text { Dose } \\
\text { Volume, } \\
\mu \mathrm{L} / \text { day }\end{array}$ & Bioavailability ${ }^{\mathrm{e}}, \%$ & $C L, L / h$ & $\begin{array}{l}\text { Plasma AUC for } \\
20 \% \text { Cortisol } \\
\text { Suppression, pg/ } \\
\text { mL*h }\end{array}$ & $\begin{array}{l}\text { Dose for } 20 \% \\
\text { Cortisol } \\
\text { Suppression, } \\
\mu \text { g/day }\end{array}$ & $\mathrm{TI}^{\mathrm{g}}$ \\
\hline $\mathrm{FF}$ & $2989^{12}$ & $4.17^{12}$ & $110^{62,63}$ & $200^{63}$ & $0.50^{62}$ & $65^{12}$ & 848 & 11,095 & 101 \\
\hline FP & $1775^{12}$ & $3.89^{12}$ & $200^{64}$ & $400[\mathrm{mg}]^{64}$ & $0.51^{34}$ & $69^{12}$ & 1332 & 18,020 & 90 \\
\hline MF & $2100^{12}$ & $4.73^{12}$ & $200^{65}$ & $400[\mathrm{mg}]^{65}$ & $0.46^{32,38}$ & $54^{12}$ & 1126 & 13,215 & 66 \\
\hline $\mathrm{CIC}^{\mathrm{h}}$ & $1200^{12}$ & $3.00^{12}$ & $200^{66}$ & $280^{66}$ & $7.4^{73, \mathrm{i}}$ & $228^{12}$ & 2158 & 6650 & 33 \\
\hline TAA & $233^{12}$ & $1.85^{12}$ & $220^{67}$ & 120 & $46^{38}$ & $37^{12}$ & 8935 & 713 & 3.2 \\
\hline FLU & $190^{12}$ & $1.36^{12}$ & $464 / 400^{68}$ & $800[\mathrm{mg}]^{68}$ & $50^{68}$ & $58^{12}$ & 10,953 & $127 \mid$ & 2.7 \\
\hline BUD & $935^{12}$ & $2.32^{12}$ & $256^{69}$ & $200^{70}$ & $31^{38}$ & $84^{12}$ & 2206 & 562 & 2.2 \\
\hline$B D P^{h}$ & $1345^{12}$ & $3.27^{12}$ & $336^{71}$ & $800[\mathrm{mg}]^{71}$ & $44^{35,38}$ & $120^{12}$ & 2179 & 594 & 1.8 \\
\hline DEX & $100^{72}$ & 1.68 & 400 & & 75 & 17 & 6750 & 154 & 0.4 \\
\hline
\end{tabular}

Notes: ${ }^{a}$ All in ANS formulation except CIC, which uses a MDI; ${ }^{b}$ Relative to DEX where DEX affinity = I00; 'Values (lipophilicity) are defined as the logI0 of the octanol/ water partition coefficient; ${ }^{\mathrm{d}}$ Therapeutic doses for AR for adults and children $(\geq 12)$ unless further specified (for $\mathrm{BDP}>12$; FLU $\geq 14$ ); ${ }^{\mathrm{e}} \mathrm{F}$, absolute bioavailability via nasal route (nose and gut absorption) determined in healthy subjects; ${ }^{\mathrm{P}} \mathrm{Plasma} \mathrm{AUC}$ ( $\mathrm{F}$ dose/CL) is the estimated daily dose that would result in $20 \%$ cortisol suppression; ${ }^{12} \mathrm{~g}$ Dose for $20 \%$ cortisol suppression/therapeutic dose; 'Values are for the active metabolites BMP and des-CIC; 'Value calculated based on Weiswasser et al J Allergy Clin Immunol. $2008,{ }^{73}$ using the clearance and relative to value for oral inhalation.

Abbreviations: ANS, aqueous nasal spray; AR, allergic rhinitis; AUC, area under the curve; BDP, beclomethasone dipropionate; BMP, beclomethasone I7-monopropionate; BUD, budesonide; CIC, ciclesonide; CL, plasma clearance; Des-CIC, desisobutyryl ciclesonide; DEX, dexamethasone; FF, fluticasone furoate; FLU, flunisolide; FP, fluticasone propionate; INCS, intranasal corticosteroid; MDI, metered-dose inhaler; MF, mometasone furoate; RRA, relative receptor affinity; TAA, triamcinolone acetonide; TI, therapeutic index.

and this correlation determines intrinsic activity of $\mathrm{CS}^{17}$ Lipophilicity also confers greater tissue affinity, with the most lipophilic and potent INCS having the highest binding affinity and retention in nasal tissue, ${ }^{17,18}$ hence higher concentrations of lipophilic FF, MF, FP, and beclomethasone-17- monopropionate are found in nasal tissue compared to lower concentrations of the more hydrophilic BUD, FLU and $\mathrm{TAA}^{17,18}$ (Figure 2). These findings provide a basis for a prolonged duration of action allowing efficacy with lower and less frequent dosing (such as once-daily dosing), notably

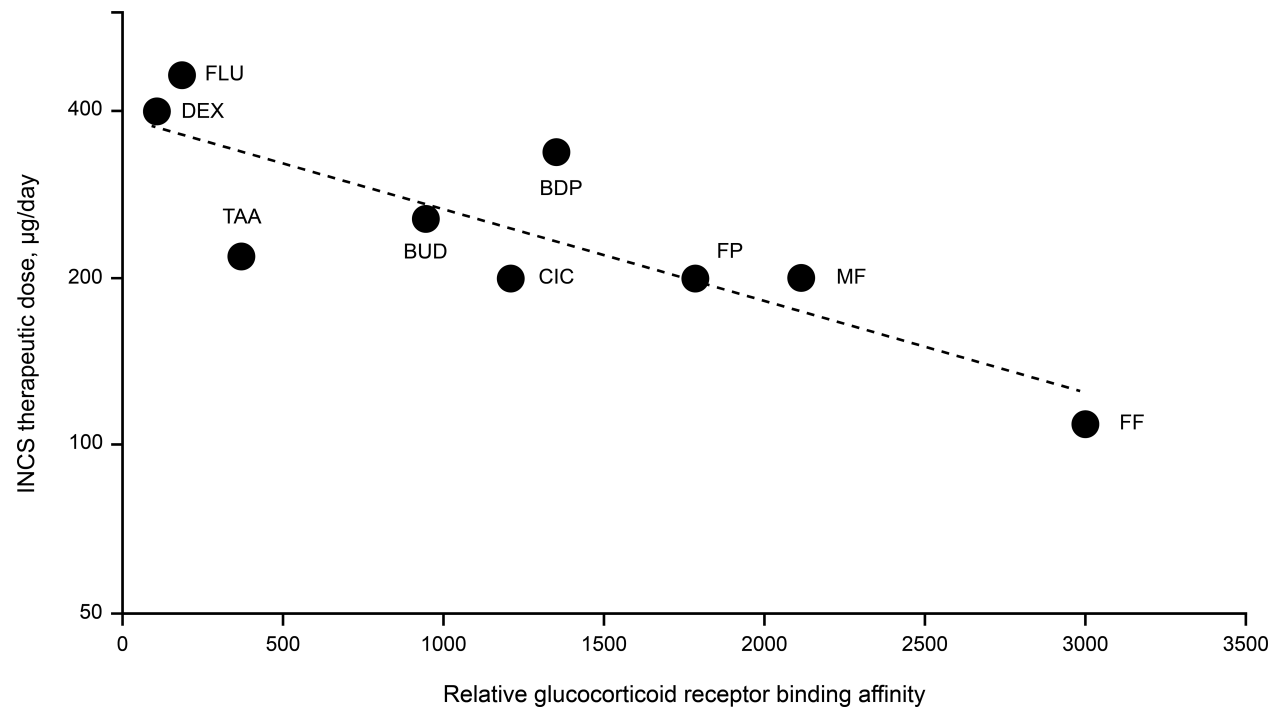

Figure I Relationship between relative glucocorticoid receptor binding affinity and therapeutic daily doses of intranasal corticosteroids $(r=0.833){ }^{12,32,34,35,38,62}$ Abbreviations: BDP, beclomethasone dipropionate; BUD, budesonide; CIC, ciclesonide; DEX, dexamethasone; FF, fluticasone furoate; FLU, flunisolide; FP, fluticasone propionate; INCS, intranasal corticosteroid; MF, mometasone furoate; TAA, triamcinolone acetonide. 


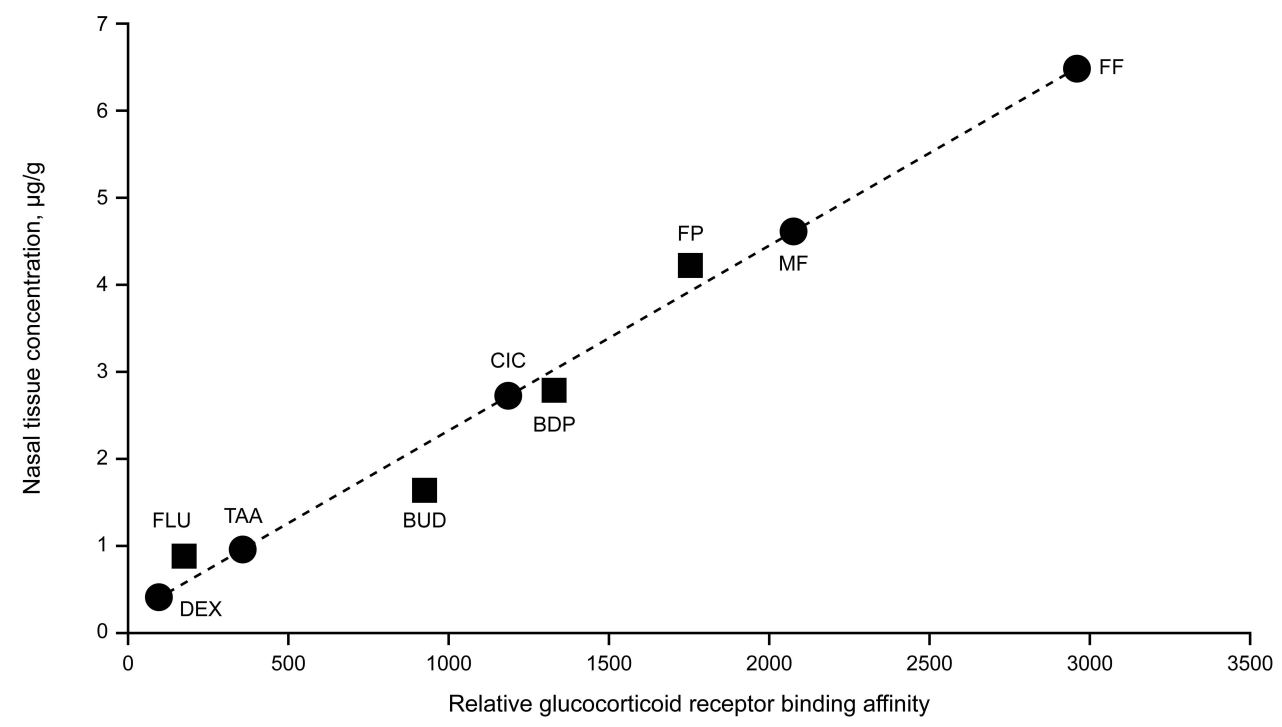

Figure 2 Relationship between relative glucocorticoid receptor binding affinity and human nasal tissue concentration (tissue binding) of intranasal corticosteroids. $^{12,32,34,35,38,62}$

Notes: Data from Esmailpour et $\mathrm{al}^{17}$ are plotted as $\mathbf{s y m b o l s}\left(\mathrm{r}^{2}=0.989\right)$; data plotted as $\bullet$ symbols are values predicted from Esmailpour et al data. ${ }^{17}$

Abbreviations: BDP, beclomethasone dipropionate; BUD, budesonide; CIC, ciclesonide; DEX, dexamethasone; FF, fluticasone furoate; FLU, flunisolide; FP, fluticasone propionate; MF, mometasone furoate; TAA, triamcinolone acetonide.

as seen for FF in AR (Table 1 and Figure 1) and for ICS in asthma. $^{19,20}$

\section{Clinical Efficacy}

The pharmacodynamic and pharmacokinetic properties of INCSs provide a basis for the anti-inflammatory topical potency of INCSs with a low incidence of adverse events. ${ }^{1}$ However, there is no evidence of a linear association between INCS topical potency and clinical response, and similarly, it is not evident that the INCS with the highest receptor affinity will have a superior therapeutic effect. ${ }^{1}$ It is possible that the extent of INCS anti-inflammatory activity needed for a therapeutic effect in AR is easily achieved by compounds with low or high potencies, because GR binding sites in nasal epithelium approach or exceed saturation with all available INCS formulations at their recommended doses. ${ }^{9,21}$ In persistent AR, a minimal dose of INCS was shown to achieve the expected clinical outcome with near maximal symptomatic control being achieved with three quarters of the recommended regular once-daily (QD) dose. ${ }^{22}$ In a dose-ranging study of FP ANS, all doses of FP studied reduced symptoms of AR significantly versus the placebo; the decrease in total symptom scores was slightly greater with the largest dose of FP (400 $\mu \mathrm{g}$ twice-daily [BID]) compared with the smallest dose (25 $\mu \mathrm{g}$ BID), but the difference was not significant. ${ }^{23}$ Results of these studies seem to confirm that there is little correlation between administered dose and clinical response of INCSs. A confounding factor in placebo-controlled trials with aqueous nasal sprays is the possibility of a significant placebo effect due to the formulation alone, since it can wash the nasal epithelium and thereby reduce antigens and inflammatory mediators. ${ }^{24-26}$

In general, clinical studies comparing the efficacy of INCSs in the treatment of AR symptoms in adults have failed to show clinically important differences between these compounds when used at recommended doses. $9,15,27$ However, there do appear to be differences in managing ocular symptoms of seasonal AR. ${ }^{28}$ The difficulty in showing a clinically important difference between INCSs is possibly due to multiple factors. Firstly, only a small fraction of the applied dose is likely to reach the site of action in the nose, which is probably why INCSs tend to be used at the top of their efficacy dose-response curves. Secondly, because INCSs have different doses (110-464 $\mu \mathrm{g} /$ day; Table 1), dosing frequencies, and potentially different durations of action, the commonly used clinical study designs and subjective endpoints generally show little or no clinically important differences between various INCSs. Finally, clinical trials of INCSs mostly include patients with moderate AR symptoms who are able to participate in a study for 2 to 4 weeks, taking only a placebo as treatment for their symptoms; whereas it might be easier to determine differences 
in clinical efficacy between various INCS by studying patients with AR who are poorly controlled with one of the INCS treatments instead. ${ }^{9}$

\section{INCS Systemic Exposure}

Although studies have shown that INCSs do not differ markedly in clinical efficacy, there are major differences between INCSs in systemic exposure. Nasal drug delivery, by spraying an aqueous suspension into the nose, is inherently inefficient due to run-off and rapid nasal ciliary clearance, which leaves only a short time-window for drug particles to form an aqueous suspension formulation, dissolve, and to be absorbed into the nasal mucosa. ${ }^{29}$ Nasal ciliary clearance removes most of the unabsorbed material usually within 30 minutes. ${ }^{30}$ However, run-off and post-nasal drip can be reduced by decreasing the spray volume in which the applied dose is administered. This volume varies considerably for the available INCS formulations (Table 1); for example, the FF ANS formulation has one of the smallest spray volumes of all available INCS, with the aim of reducing run-off and improving drug delivery to the nasal tissue. Even so, only a small fraction of the applied dose reaches the site of action as the majority of the dose is eventually swallowed, ${ }^{29}$ direct absorption into the circulation via the nasal mucosa is therefore low, especially for highly insoluble lipophilic $\operatorname{INCSs}^{29}$ when administered as ANS suspension formulations. $^{31,32}$ The swallowed portion of the dose becomes available for absorption from the gastrointestinal tract. For some INCS, a high rate of first-pass metabolism will inactivate the absorbed dose but any direct absorption into the circulation via the nasal mucosa bypasses the hepatic first-pass mechanism. ${ }^{1,33}$ Consequently, the systemic exposure of an INCS depends primarily on its oral bioavailability with only a minor contribution from the nasally absorbed fraction. ${ }^{32-35}$ Therefore the systemic bioavailability of different INCSs varies greatly, with the highest values reported for DEX (75\%) and FLU (50\%), and the lowest values reported for FF, MF, and FP (all $<1 \%$ ) (Table 1). Low systemic exposures of INCSs at their therapeutic doses are generally due to the low dose and bioavailability and high systemic clearance (Table 1). Although the half-life of INCSs vary widely, between $1.5 \mathrm{~h}$ to $20 \mathrm{~h}$ for TAA and FF respectively, this is a consequence of their clearance and volume of distribution, which are both high for all glucocorticoid molecules, although higher for more lipophilic glucocorticoids. ${ }^{12}$ The half-life does not determine the extent of systemic exposure, only the time it takes to reach steady-state during repeated dosing. The extent of systemic exposure is governed by the rate of systemic clearance, which increases with lipophilicity. Therefore, INCSs with higher potency also have higher systemic clearance rates as their higher lipophilicity increases their affinity for hepatic drug metabolizing enzymes (cytochrome P450 3A4). ${ }^{12}$

Hypothalamic-pituitary-adrenal (HPA) axis suppression is a sensitive marker of the potential risk for adverse events related to systemic $\mathrm{CS},{ }^{36}$ and, in children, growth suppression has been identified as a sensitive endpoint for assessing systemic activity of $\mathrm{CS}^{37}$ The INCS dose required to produce even a low level of systemic activity (cortisol suppression $\leq 20 \%$ ) varies from many multiples of the therapeutic dose for FF, FP, MF and CIC (33-101 times), several multiples of the therapeutic dose for BDP, BUD, TAA, FLU (1.8-3.2 times), to less than the therapeutic dose for DEX (0.4) (Table 1). The systemic exposure of INCS is generally regarded as low compared to systemic CS use, ${ }^{38}$ however, systemic exposure of INCS may still be significant and result in adverse effects for molecules with high bioavailability (eg DEX, FLU, TAA; Table 1$).{ }^{39}$

\section{Therapeutic Index}

Differences in the extent of systemic exposure between INCSs are translated into differences in therapeutic index. The therapeutic index is defined here as the ratio of the dose that causes measurable systemic activity (defined as the dose for $20 \%$ cortisol suppression) divided by the therapeutic dose. Therapeutic index estimates for available INCSs, as shown in Table 1, demonstrate a strong correlation with GR binding affinity $\left(\mathrm{r}^{2}=0.881\right.$; Figure 1$)$. INCS with higher GR binding affinity generally have a higher therapeutic index (eg, FF, FP, MF), and those with lower GR binding affinity generally have a lower therapeutic index (eg, TAA, FLU, DEX; Figure 3). Therapeutic index estimates also demonstrate an inverse correlation with systemic bioavailability where INCSs with lower bioavailability have a higher therapeutic index than those with higher bioavailability (Figure 4).

These findings are likely due to a higher GR binding affinity being associated with higher nasal tissue uptake and retention compared with an INCS with a lower GR binding affinity. A higher GR binding affinity in turn lowers oral bioavailability and increases systemic clearance because, as explained above, the higher lipophilicity found with more potent INCSs also renders them better substrates for hepatic 


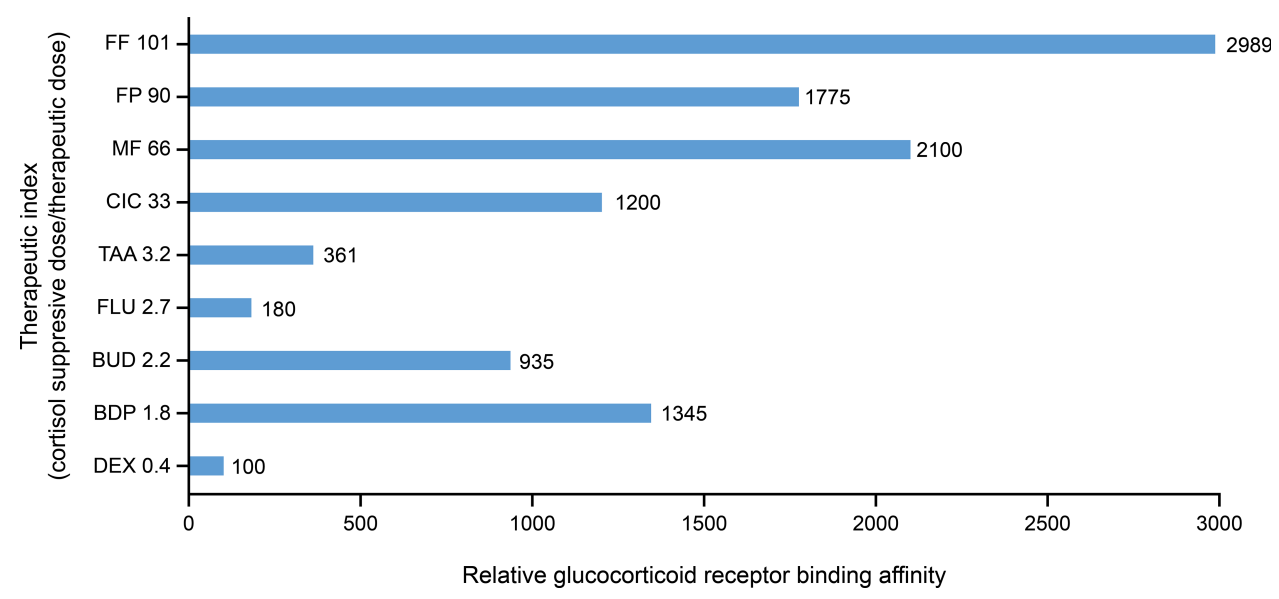

Figure 3 Relationship between relative glucocorticoid receptor binding affinity and the therapeutic index for various intranasal corticosteroids. ${ }^{12,32,34,35,38,62}$

Notes: The therapeutic index is defined here as the ratio of the dose that causes measurable systemic activity (defined as dose for cortisol suppression) divided by the therapeutic dose.

Abbreviations: BDP, beclomethasone dipropionate; BUD, budesonide; CIC, ciclesonide; DEX, dexamethasone; FF, fluticasone furoate; FLU, flunisolide; FP, fluticasone propionate; MF, mometasone furoate; TAA, triamcinolone acetonide.

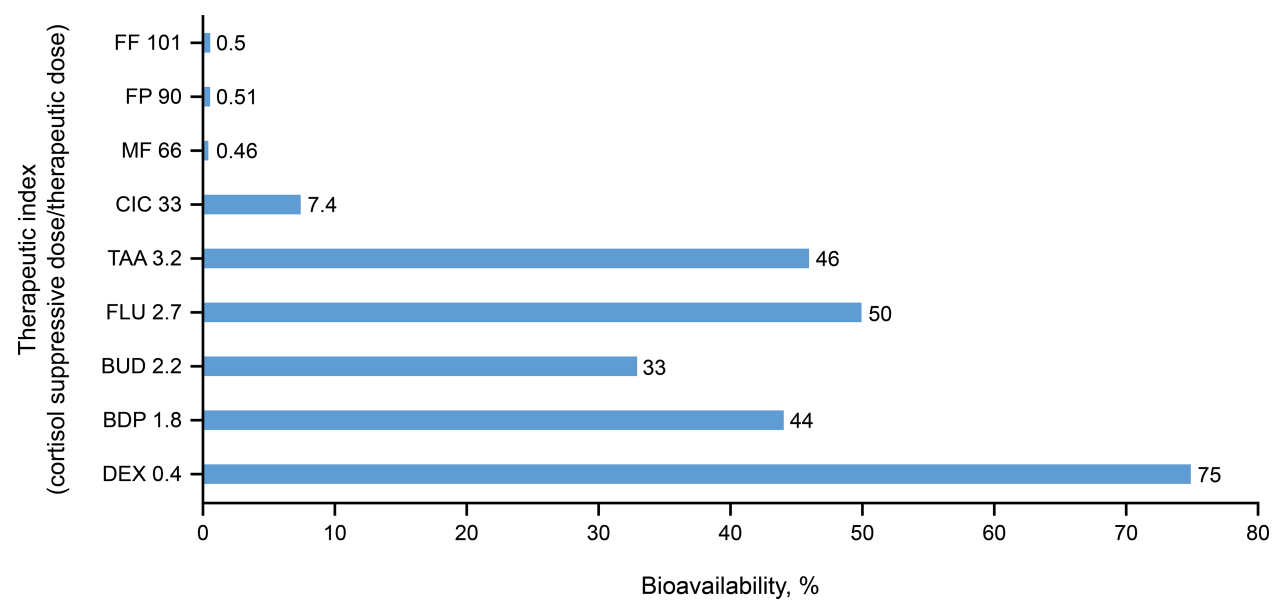

Figure 4 Relationship between systemic bioavailability and the therapeutic index for various intranasal corticosteroids. ${ }^{12,32,34,35,38,62}$

Notes: The therapeutic index is defined here as the ratio of the dose that causes measurable systemic activity (defined as dose for cortisol suppression) divided by the therapeutic dose.

Abbreviations: BDP, beclomethasone dipropionate; BUD, budesonide; CIC, ciclesonide; DEX, dexamethasone; FF, fluticasone furoate; FLU, flunisolide; FP, fluticasone propionate; MF, mometasone furoate; TAA, triamcinolone acetonide.

drug metabolizing enzymes. Together these factors reduce systemic exposure. These differences in therapeutic indexes between INCSs mainly reflect differing degrees of systemic exposure between treatments, which has the potential to result in reduced systemic side-effects.

\section{Effect of Intranasal Corticosteroids on Growth Rate in Children}

While the systematic review and meta-analysis from 2020 showed that INCSs in adults are generally safe, ${ }^{40}$ concerns have been raised about the potential adverse events of chronic INCS use on growth in children, ${ }^{41,42}$ despite conflicting evidence for this being available in published studies. For example, use of BDP ANS (168 $\mu \mathrm{g}$ BID) was shown to significantly affect growth rate in children after one year of treatment, ${ }^{43}$ and BUD MDI (200 $\mu \mathrm{g}$ BID) was found to significantly reduce lower-leg growth in children after six weeks of treatment. ${ }^{44}$ However, other studies of INCS use in pediatric populations (with MF ANS [100 $\mu \mathrm{g}$ QD $],{ }^{45}$ BUD MDI $[256-400 \mu \mathrm{g} \mathrm{BID}]^{46}$ or BUD ANS [64 $\mu \mathrm{g}$ $\mathrm{QD}]^{47}$ ) have not shown effects on growth in children after 1-2 years of treatment. Another study found that FF ANS $(110 \mu \mathrm{g}$ QD) had no effect on lower-leg growth rate in prepubertal children after two weeks of treatment, ${ }^{48}$ while one-year treatment with FF ANS in prepubertal children did 
demonstrate a small reduction in growth without any other safety issue identified. ${ }^{49,50}$ Growth velocity in children treated with nasal CIC has not been studied at the time of this review, ${ }^{51}$ however, inhaled QD doses of CIC 40-160 $\mu \mathrm{g}$ were not found to significantly affect growth of children with asthma. ${ }^{52}$ The impact of long-term treatment with INCS on adult height has not been studied, ${ }^{41}$ but results of growth studies of ICS in children with asthma show little or no reduction in final adult height. ${ }^{41,53,54}$

A meta-analysis of 32 published pediatric studies ${ }^{37}$ (including 12 studies of INCSs, conducted before June 2003) was conducted to determine the effect of CS on growth velocity, assessed by either knemometry (studies of a few weeks duration measuring lower leg growth rate) or stadiometry (studies typically of 1 year duration measuring standing height). The approach from this study related the normal endogenous CS production rate to the exogenous contributions from ICS by converting them into cortisol equivalent exposures. This approach takes into account the bioavailability, the relative GR binding affinity and systemic clearance of the CS, to express the systemic exposure for each CS as a cortisol-equivalent area under the plasma concentration-time curve. It was concluded that growth effects were nonlinearly related to CS exposure and change in growth velocity was highly correlated with CS exposure, irrespective of the route of administration. INCSs with high systemic bioavailability (BDP, BUD, TAA) were predicted to have short-term growth effects exceeding the clinical equivalence limit for change in growth velocity $( \pm 0.8 \mathrm{~cm} /$ y); INCSs with lower bioavailability (FP, MF) were predicted to produce systemic exposures below the threshold for significant effects on growth velocity (Figure 5). In ascending order, the model predicted the following rankings of potential, expressed as fractions or multiples of the pediatric dose (in $\mu \mathrm{g} / \mathrm{d}$ ), of the various INCSs to reduce growth velocity: TAA ANS $=0.74(220 \mu \mathrm{g} / \mathrm{d}) ; \mathrm{BDP}$ ANS $=0.89(336$ $\mu \mathrm{g} / \mathrm{d})$; BUD ANS=2.5 (128 $\mu \mathrm{g}) ; \mathrm{MF}$ ANS=120 $(100 \mu \mathrm{g} / \mathrm{d})$; and FP ANS $=150(100 \mu \mathrm{g} / \mathrm{d})$. Values $>1$ are predictive of no significant effect on growth velocity. Although this analysis did not include FF and CIC, its findings and findings from other available studies demonstrate that INCSs with low systemic bioavailabilities have a low potential for growth effects in children. The analysis concluded that a no-effect dose for growth effects should be possible for INCS with low systemic bioavailability.

Children in particular often receive concurrent ICS and INCS therapy for asthma and AR, respectively. ${ }^{55}$ While the impact of low-dose ICS and INCS monotherapy on child growth velocity have been extensively studied, ${ }^{43,45,53,54,56,57}$ and have shown to either not affect or transiently reduce

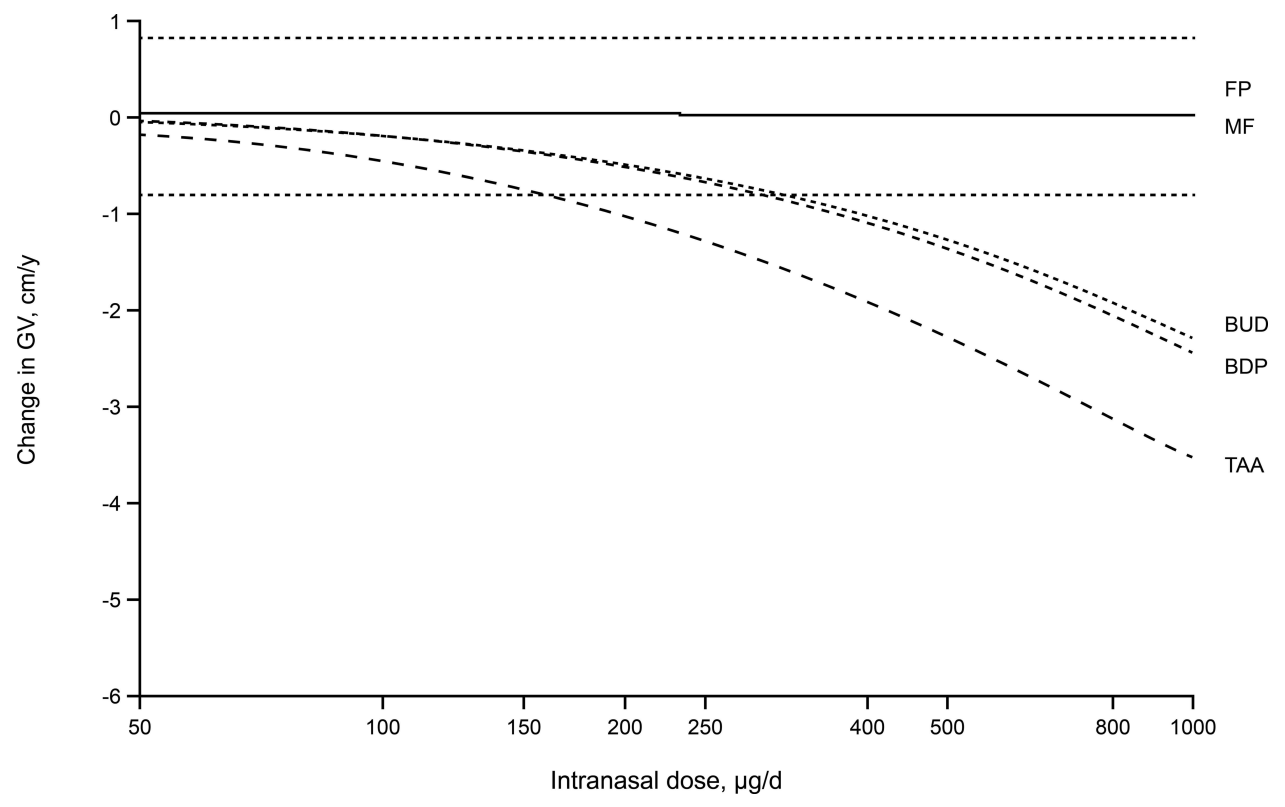

Figure 5 Model-predicted changes in annual growth velocity for a range of doses of intranasal corticosteroids above and below the standard pediatric therapeutic doses. Reprinted from Clin Ther, 26(I I), Daley-Yates PT, Richards DH. Relationship between systemic corticosteroid exposure and growth velocity: development and validation of a pharmacokinetic/pharmacodynamic model, 1905-1919, Copyright (2004), with permission from Elsevier. ${ }^{37}$

Notes: The dotted lines indicate clinical equivalence limits of $\pm 0.8 \mathrm{~cm} / \mathrm{y}$.

Abbreviations: BDP, beclomethasone dipropionate; BUD, budesonide; FP, fluticasone propionate; GV, growth velocity; MF, mometasone furoate; TAA, triamcinolone acetonide. 
growth, there remains a lack of data on growth effects for concurrent ICS and INCS therapy. The study modeling the relationship between systemic CS exposure and growth velocity $^{37}$ also analyzed the concurrent administration of ICSs and INCSs in children. The authors concluded that both ICS and INCS with high systemic bioavailability (BDP, TAA and BUD) could have short-term effects on growth $( \pm 0.8 \mathrm{~cm} / \mathrm{y})$, whereas CSs with lower systemic bioavailability (FP and MF) were predicted to produce systemic exposures below the threshold for significant effects on growth velocity, and to show an adequate safety margin even with concurrent administration (Figure 6); it seems there is a threshold dose or exposure required to achieve a clinically significant effect. These predictions are supported by results of the study in which co-administration of ICS and INCS had no significant effects on HPA-axis function in children. ${ }^{58}$ Small changes in growth velocity seen in short-term studies may have minor clinical relevance, however, since differences in growth velocity between formulations with higher and lower systemic bioavailability have been demonstrated it is desirable to select products that minimize this effect particularly when used frequently. ${ }^{21}$

\section{Discussion}

In this narrative review we assessed the therapeutic relevance of GR binding affinity, topical potency, physicochemical and pharmacokinetic properties of INCS, and explored the relationship between topical potency and therapeutic index. Data presented in this review has been derived and/or directly extrapolated from results of different INCSs studies found in the available literature.

Higher GR binding affinity of INCS is associated with higher nasal tissue uptake and retention which together result in higher topical potency. These features tend to cooccur with lower oral bioavailability and higher systemic clearance, leading to reduced systemic exposure and reduced potential for adverse events which here we have expressed as differences in therapeutic index. Moreover, highly lipophilic INCS have high tissue binding affinity and tissue retention which are important properties of topically applied CS. These properties are the basis of prolonged duration of action in the nose and result in effective treatment of AR with once-daily dosing as seen with the more lipophilic INCS, ${ }^{15}$ such as FP, MF and FF. The pharmacodynamic and pharmacokinetic properties of INCSs result in clinical efficacy with a low occurrence of adverse events. Although the approved therapeutic doses of INCSs correlate with topical potency (GR binding affinity) (Figure 1), the range of approved therapeutic doses is narrow compared to the range of GR binding affinity. Furthermore, the approved therapeutic doses of all INCS molecules appear to be at the top of the efficacy dose response curve, which may explain why clinical efficacy studies often fail differentiate between INCS marketed drug products.

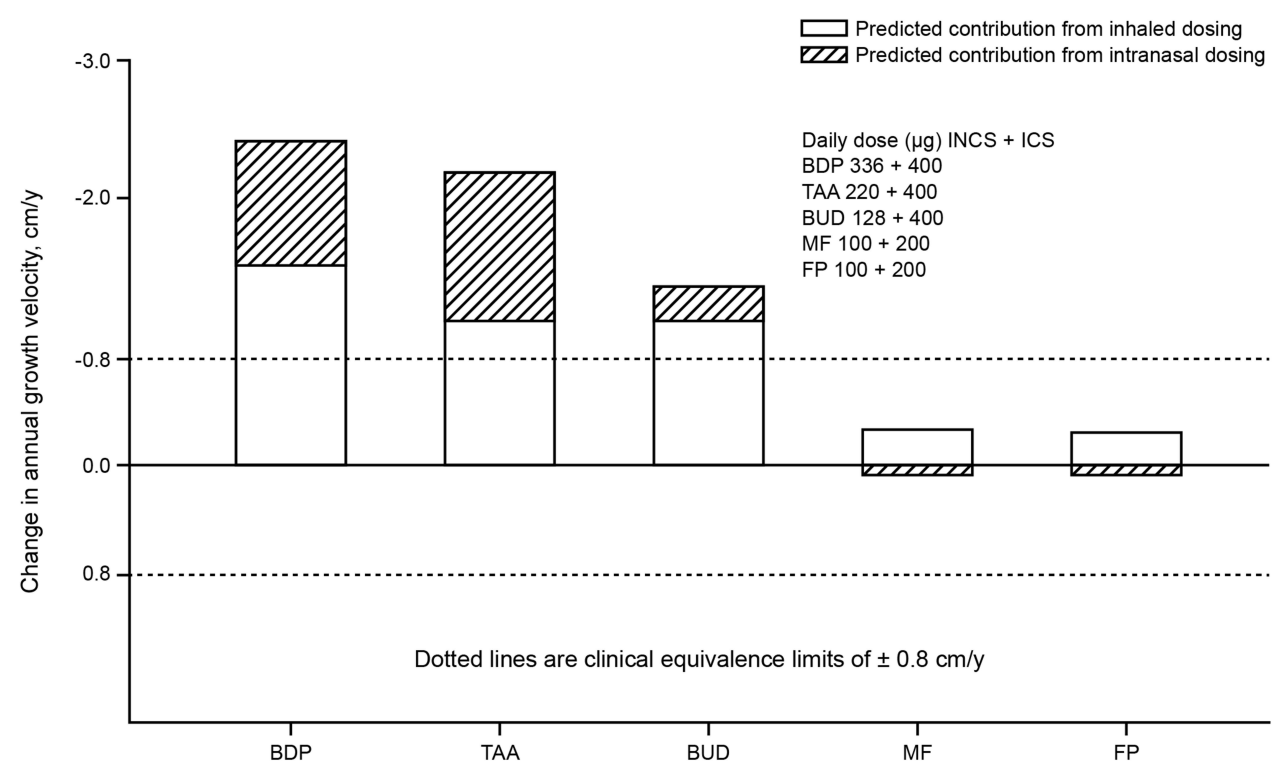

Figure 6 Model-predicted changes in annual growth velocity for combined inhaled and intranasal corticosteroid regimens. Adapted from Clin Ther, 26(I I), Daley-Yates PT, Richards DH. Relationship between systemic corticosteroid exposure and growth velocity: development and validation of a pharmacokinetic/pharmacodynamic model, I9051919, Copyright (2004), with permission from Elsevier. ${ }^{37}$

Abbreviations: BDP, beclomethasone dipropionate; BUD, budesonide; FP, fluticasone propionate; ICS, inhaled corticosteroids; INCS, intranasal corticosteroid; MF, mometasone furoate; TAA, triamcinolone acetonide. 
It could be argued that the second-generation INCSs (CIC, FP, MF, FF) have pharmacokinetic/pharmacodynamic properties of the "ideal" INCS because of a high GR binding affinity, GR specificity and topical potency, low systemic availability, and once-daily dosing frequency. These properties are the result of attempts to design molecules with a higher ratio of topical-to-systemic activity and thereby improve the therapeutic index. The second-generation INCSs have an improved therapeutic index compared to the first-generation INCSs; the second-generation FF has the highest (101) and the first-generation DEX the lowest (0.4) therapeutic index from all currently available INCSs (Table 1). The first-generation INCS, however, have a substantially improved therapeutic index compared to oral CS. Although the second-generation INCSs differ in physicochemical and pharmacokinetic properties from the first-generation INCSs, and from each other, it is not evident whether these properties translate to clinically important differences in efficacy. This could be because there is a lack of head-to-head comparisons of INCSs in clinical studies conducted in more severe AR patients. In 2011, Schafer et $\mathrm{al}^{14}$ provided a differentiated summary of clinically important features of INCSs, however, the studies utilized different methodologies and subjective endpoints, which showed little or no clinically important differences between various INCS therapies. Also, because INCSs differ in pharmacokinetic properties, including systemic absorption and activity after administration, studies using different INCSs and delivery devices such as ANS and MDI may not be directly comparable to each other. ${ }^{59}$ Differences in, for example, performance and ease-ofuse of different delivery devices, and patient compliance to these devices may confound the results of comparative studies of INCSs. ${ }^{41,60}$ This narrative review compared INCSs using pharmacological principles, rather than clinical endpoints alone, allowing for a more robust comparison of different INCS therapies.

The impact of concurrent administration of CS (eg, ICS and INCS) has not been well studied, but combined treatments could increase a total systemic CS load. Although INCS dose regimens mostly produce low systemic exposure and systemic effects, use of an INCS with low systemic exposure in patients on multiple CS therapies could help reduce the total systemic burden of CS therapy. The impact of concurrent administration of CS has been studied in children, ${ }^{37,58}$ but the possibility for an increased systemic effect should also be considered in adults treated with CS for multiple conditions.

Several studies have assessed the effect of INCS on growth in children, ${ }^{37}$ however, this assessment is largely a regulatory requirement for marketing authorization and product labelling because the risk of growth suppression with the relatively short-term use of INCS at low doses is low. When assessing the effects of CS on growth in children it is important to note that growth may be divided into three distinct age-related phases and that in each of these three phases there are different factors affecting growth. The studies reported in this review considered different age groups (eg, 5 15 years or 5-8 years), therefore results from studies on one age group cannot be compared to the results from other age groups. Nevertheless, there is a general trend that adverse events related to systemic exposure of INCS in children are low. To determine the potential impact of INCSs on growth in children, studies should be performed during each phase of growth. ${ }^{41}$ The Food and Drug Administration recommends that growth studies are conducted during the so-called growth hormone-dependent phase between the infant/ toddler and pubescent growth periods when there is a relatively constant background growth velocity; this provides accurate measurement and a less confounded comparison of INCSs over time. ${ }^{61}$ The most important clinical outcome in growth studies is final adult height. Interestingly, the effect of CS on growth from shortor intermediate-term studies (2-week knemometry studies or 1-year stadiometry studies) does not correlate with the effect on final adult height. ${ }^{41}$ The results of meta-analyses of growth studies in children may also differ due to different ways of consolidating data or incorrect assumptions about the level of adherence to therapy in long-term studies. In many studies, CS systemic exposure was assumed to be related to the administered dose, while systemic exposure might be better expressed in cortisol equivalents or another method of accounting for pharmacokinetic and pharmacodynamic differences between molecules.

A limitation of this review was the inability to directly compare available INCSs. This was due to the lack of publications reporting head-to-head INCS clinical studies, as well as the use of data of inconsistent quality derived from different INCS studies. 


\section{Conclusions}

In conclusion, higher GR binding affinity and topical potency can potentially improve the therapeutic index of an INCS. Therefore, both efficacy and systemic exposure profiles should be considered when comparing INCS regimens in terms of therapeutic equivalence, in order to aid clinical decision-making and ensure the most appropriate treatment options are considered on an individual basis.

\section{Abbreviations}

$\mathrm{AR}$, allergic rhinitis; ANS, aqueous nasal spray; AUC, area under the curve; BDP, beclomethasone dipropionate; BID, twice daily; BMP, beclomethasone 17-monopropionate; BUD, budesonide; CIC, ciclesonide; CL, plasma clearance; CS, corticosteroids; Des-CIC, desisobutyryl ciclesonide; DEX, dexamethasone, $\mathrm{FF}$, fluticasone furoate; FLU, flunisolide; FP, fluticasone propionate; GR, glucocorticoid receptor; GV, growth velocity; HPA, Hypothalamic-pituitary-adrenal; ICS, inhaled corticosteroids; INCS, Intranasal corticosteroids; MDI, metered-dose inhalers; MF, mometasone furoate; QD, once daily; RRA, relative receptor affinity; TAA, triamcinolone acetonide, TI, therapeutic index.

\section{Data Sharing Statement}

Information on GSK's data sharing commitments and requesting access to anonymized individual participant data and associated documents can be found at www. clinicalstudydatarequest.com.

\section{Acknowledgments}

Medical writing support for the development of this manuscript, under the direction of the authors, was provided by Zofia Zgrundo, MSc, and Andrew Briggs, BA, of Ashfield MedComms, an Ashfield Health company, and funded by GlaxoSmithKline plc.

\section{Author Contributions}

All authors made a significant contribution to the work reported, whether that was in the conception, study design, execution, acquisition of data, analysis and interpretation, or in all these areas; took part in drafting, revising or critically reviewing the article; gave final approval of the version to be published; have agreed on the journal to which the article has been submitted; and agreed to be accountable for all aspects of the work.

\section{Funding}

This review article was funded by GlaxoSmithKline plc.

\section{Disclosure}

PDY, CB and MV are employees of GlaxoSmithKline plc. and own stocks/shares in the company. DLL reports personal fees from Allakos, Armstrong, AstraZeneca, DBV Technologies, Grunenthal, GlaxoSmithKline plc., Mylan, Menarini, MSD, Novartis, Pfizer, Sanofi, Siegfried, UCB, Alakos, Gossamer, grants from Sanofi, AstraZeneca, Novartis, Circassia, UCB, GlaxoSmithKline plc., TEVA, Purina institute, Carnot, and Viatris, outside the submitted work. The authors report no other conflicts of interest in this work.

\section{References}

1. Derendorf H, Meltzer EO. Molecular and clinical pharmacology of intranasal corticosteroids: clinical and therapeutic implications. Allergy. 2008;63(10):1292-1300. doi:10.1111/j.13989995.2008.01750.x

2. Juel-Berg N, Darling P, Bolvig J, et al. Intranasal corticosteroids compared with oral antihistamines in allergic rhinitis: a systematic review and meta-analysis. Am J Rhinol Allergy. 2017;31(1):19-28. doi:10.2500/ajra.2016.30.4397

3. Wallace DV, Dykewicz MS, Bernstein DI, et al. The diagnosis and management of rhinitis: an updated practice parameter. J Allergy Clin Immunol. 2008;122(2 Suppl):S1-S84. doi:10.1016/j.jaci.2008.06.003

4. Scadding GK. Corticosteroids in the treatment of pediatric allergic rhinitis. J Allergy Clin Immunol. 2001;108(1 Suppl):S59-S64. doi:10.1067/mai.2001.115568

5. Bensch GW. Safety of intranasal corticosteroids. Ann Allergy Asthma Immunol. 2016;117(6):601-605. doi:10.1016/j.anai.2016.06.009

6. Sheth K. Evaluating the safety of intranasal steroids in the treatment of allergic rhinitis. Allergy Asthma Clin Immunol. 2008;4 (3):125-129. doi:10.1186/1710-1492-4-3-125

7. Şimşek A, Bayraktar C, Doğan S, Karataş M, Sarıkaya Y. The effect of long-term use of intranasal steroids on intraocular pressure. Clin Ophthalmol. 2016;10:1079-1082. doi:10.2147/OPTH.S106392

8. Chong LY, Head K, Hopkins C, Philpott C, Burton MJ, Schilder AG. Different types of intranasal steroids for chronic rhinosinusitis. Cochrane Database Syst Rev. 2016;4:Cd011993.

9. Corren J. Intranasal corticosteroids for allergic rhinitis: how do different agents compare? J Allergy Clin Immunol. 1999;104(4 Pt 1): S144-149. doi:10.1016/S0091-6749(99)70310-6

10. Hankin CS, Cox L, Lang D, et al. Medical costs and adherence in patients receiving aqueous versus pressurized aerosol formulations of intranasal corticosteroids. Allergy Asthma Proc. 2012;33(3):258-264. doi:10.2500/aap.2012.33.3565

11. Meltzer EO. Formulation considerations of intranasal corticosteroids for the treatment of allergic rhinitis. Ann Allergy Asthma Immunol. 2007;98(1):12-21. doi:10.1016/S1081-1206(10)60854-X

12. Daley-Yates PT. Inhaled corticosteroids: potency, dose equivalence and therapeutic index. Br J Clin Pharmacol. 2015;80(3):372-380. doi:10.1111/bcp. 12637

13. Lumry WR. A review of the preclinical and clinical data of newer intranasal steroids used in the treatment of allergic rhinitis. $J$ Allergy Clin Immunol. 1999;104(4 Pt 1):S150-158. doi:10.1016/S00916749(99)70311-8

14. Schafer T, Schnoor M, Wagenmann M, Klimek L, Bachert C. Therapeutic Index (TIX) for intranasal corticosteroids in the treatment of allergic rhinitis. Rhinology. 2011;49(3):272-280. 
15. Herman H. Once-daily administration of intranasal corticosteroids for allergic rhinitis: a comparative review of efficacy, safety, patient preference, and cost. Am J Rhinol. 2007;21(1):70-79. doi:10.2500/ ajr.2007.21.2896

16. van Cauwenberge P, Van Hoecke H, Vandenbulcke L, Van Zele T, Bachert C. Glucocorticosteroids in allergic inflammation: clinical benefits in allergic rhinitis, rhinosinusitis, and otitis media. Immunol Allergy Clin North Am. 2005;25(3):489-509. doi:10.1016/j. iac.2005.05.001

17. Esmailpour N, Högger P, Rohdewald P. Binding of glucocorticoids to human nasal tissue in vitro. Int Arch Allergy Immunol. 2000;122 (2):151-154. doi:10.1159/000024371

18. Baumann D, Bachert C, Högger P. Dissolution in nasal fluid, retention and anti-inflammatory activity of fluticasone furoate in human nasal tissue ex vivo. Clin Exp Allergy. 2009;39(10):1540-1550. doi:10.1111/j.1365-2222.2009.03306.x

19. Bardsley G, Daley-Yates P, Baines A, et al. Anti-inflammatory duration of action of fluticasone furoate/vilanterol trifenatate in asthma: a cross-over randomised controlled trial. Respir Res. 2018;19(1):133. doi:10.1186/s12931-018-0836-6

20. Daley-Yates P, Brealey N, Kumar B, et al. Therapeutic index of inhaled corticosteroids in asthma: a dose-response comparison on airway hyperresponsiveness and adrenal axis suppression. $\mathrm{Br} \mathrm{J}$ Clin Pharmacol. 2020;87(2):1-11. doi:10.1111/bcp.14406.

21. Stellato C, Atsuta J, Bickel CA, Schleimer RP. An in vitro comparison of commonly used topical glucocorticoid preparations. J Allergy Clin Immunol. 1999;104(3 Pt 1):623-629. doi:10.1016/S00916749(99)70334-9

22. Kirtsreesakul V, Chansaksung P, Ruttanaphol S. Dose-related effect of intranasal corticosteroids on treatment outcome of persistent allergic rhinitis. Otolaryngol Head Neck Surg. 2008;139(4):565-569. doi:10.1016/j.otohns.2008.07.023

23. Meltzer EO, Orgel HA, Bronsky EA, et al. A dose-ranging study of fluticasone propionate aqueous nasal spray for seasonal allergic rhinitis assessed by symptoms, rhinomanometry, and nasal cytology. J Allergy Clin Immunol. 1990;86(2):221-230. doi:10.1016/S00916749(05)80069-7

24. Vasar M, Houle PA, Douglass JA, et al. Fluticasone furoate nasal spray: effective monotherapy for symptoms of perennial allergic rhinitis in adults/adolescents. Allergy Asthma Proc. 2008;29 (3):313-321. doi:10.2500/aap.2008.29.3126

25. Nathan RA, Berger W, Yang W, et al. Effect of once-daily fluticasone furoate nasal spray on nasal symptoms in adults and adolescents with perennial allergic rhinitis. Ann Allergy Asthma Immunol. 2008;100 (5):497-505. doi:10.1016/S1081-1206(10)60477-2

26. Kaiser HB, Naclerio RM, Given J, et al. Fluticasone furoate nasal spray: a single treatment option for the symptoms of seasonal allergic rhinitis. $J$ Allergy Clin Immunol. 2007;119(6):1430-1437. doi:10.1016/j.jaci.2007.02.022

27. Nielsen LP, Mygind N, Dahl R. Intranasal corticosteroids for allergic rhinitis: superior relief? Drugs. 2001;61(11):1563-1579. doi:10.2165/ 00003495-200161110-00004

28. Keith PK, Scadding GK. Are intranasal corticosteroids all equally consistent in managing ocular symptoms of seasonal allergic rhinitis? Curr Med Res Opin. 2009;25(8):2021-2041. doi:10.1185/ 03007990903094106

29. Lipworth BJ, Jackson CM. Safety of inhaled and intranasal corticosteroids: lessons for the new millennium. Drug Saf. 2000;23(1):11-33. doi:10.2165/00002018-200023010-00002

30. Schipper NG, Verhoef JC, Merkus FW. The nasal mucociliary clearance: relevance to nasal drug delivery. Pharm Res. 1991;8 (7):807-814. doi:10.1023/A:1015830907632

31. Allen DB. Systemic effects of intranasal steroids: an endocrinologist's perspective. J Allergy Clin Immunol. 2000;106(4 Suppl):S179190. doi:10.1067/mai.2000.110038
32. Daley-Yates PT, Kunka RL, Yin Y, Andrews SM, Callejas S, Ng C. Bioavailability of fluticasone propionate and mometasone furoate aqueous nasal sprays. Eur J Clin Pharmacol. 2004;60(4):265-268. doi:10.1007/s00228-004-0763-y

33. Szefler SJ. Pharmacokinetics of intranasal corticosteroids. J Allergy Clin Immunol. 2001;108(1 Suppl):S26-31. doi:10.1067/mai.2001.115563

34. Daley-Yates PT, Baker RC. Systemic bioavailability of fluticasone propionate administered as nasal drops and aqueous nasal spray formulations. $\mathrm{Br} J$ Clin Pharmacol. 2001;51(1):103-105. doi:10.1046/j.1365-2125.2001.01325.x

35. Daley-Yates PT, Price AC, Sisson JR, Pereira A, Dallow N. Beclomethasone dipropionate: absolute bioavailability, pharmacokinetics and metabolism following intravenous, oral, intranasal and inhaled administration in man. Br J Clin Pharmacol. 2001;51 (5):400-409. doi:10.1046/j.0306-5251.2001.01374.x

36. Dluhy RG. Clinical relevance of inhaled corticosteroids and HPA axis suppression. J Allergy Clin Immunol. 1998;101(4 Pt 2):S447S450. doi:10.1016/S0091-6749(98)70157-5

37. Daley-Yates PT, Richards DH. Relationship between systemic corticosteroid exposure and growth velocity: development and validation of a pharmacokinetic/pharmacodynamic model. Clin Ther. 2004;26 (11):1905-1919. doi:10.1016/j.clinthera.2004.11.017

38. Daley-Yates P, Richards DH. Pharmacokinetics (PK) and Pharmacodynamic (PD) relationships for Intranasal Corticosteroids (INCS). J Allergy Clin Immunol. 2001;107(2, Supplement):S313.

39. Kimmerle R, Rolla AR. Iatrogenic Cushing's syndrome due to dexamethasone nasal drops. Am J Med. 1985;79(4):535-537. doi:10.1016/0002-9343(85)90046-4

40. Donaldson AM, Choby G, Kim DH, Marks LA, Lal D. Intranasal corticosteroid therapy: systematic review and meta-analysis of reported safety and adverse effects in adults. Otolaryngol Head Neck Surg. 2020;163(6):1097-1108. doi:10.1177/0194599820931455

41. Pedersen S. Assessing the effect of intranasal steroids on growth. J Allergy Clin Immunol. 2001;108(1 Suppl):S40-S44. doi:10.1067/ mai.2001.115565

42. Mener DJ, Shargorodsky J, Varadhan R, Lin SY. Topical intranasal corticosteroids and growth velocity in children: a meta-analysis. Int Forum Allergy Rhinol. 2015;5(2):95-103. doi:10.1002/alr.21430

43. Skoner DP, Rachelefsky GS, Meltzer EO, et al. Detection of growth suppression in children during treatment with intranasal beclomethasone dipropionate. Pediatrics. 2000;105(2):E23. doi:10.1542/ peds.105.2.e23

44. Wolthers OD, Pedersen S. Short-term growth in children with allergic rhinitis treated with oral antihistamine, depot and intranasal glucocorticosteroids. Acta Paediatr. 1993;82(8):635-640. doi:10.1111/j.1651-2227.1993.tb18030.x

45. Schenkel EJ, Skoner DP, Bronsky EA, et al. Absence of growth retardation in children with perennial allergic rhinitis after one year of treatment with mometasone furoate aqueous nasal spray. Pediatrics. 2000;105(2):E22. doi:10.1542/peds.105.2.e22

46. Möller C, Ahlström H, Henricson KA, Malmqvist LA, Akerlund A, Hildebrand H. Safety of nasal budesonide in the long-term treatment of children with perennial rhinitis. Clin Exp Allergy. 2003;33 (6):816-822. doi:10.1046/j.1365-2222.2003.01689.x

47. Murphy K, Uryniak T, Simpson B, O’Dowd L. Growth velocity in children with perennial allergic rhinitis treated with budesonide aqueous nasal spray. Ann Allergy Asthma Immunol. 2006;96(5):723-730. doi:10.1016/S1081-1206(10)61072-1

48. Gradman J, Caldwell MF, Wolthers OD. A 2-week, crossover study to investigate the effect of fluticasone furoate nasal spray on short-term growth in children with allergic rhinitis. Clin Ther. 2007;29(8):1738-1747. doi:10.1016/j.clinthera.2007.08.017

49. Bateman ED, O'Byrne PM, Busse WW, et al. Once-daily fluticasone furoate $(\mathrm{FF}) /$ vilanterol reduces risk of severe exacerbations in asthma versus FF alone. Thorax. 2014;69(4):312-319. doi:10.1136/thoraxjnl2013-203600 
50. Lee LA, Sterling R, Máspero J, Clements D, Ellsworth A, Pedersen S. Growth velocity reduced with once-daily fluticasone furoate nasal spray in prepubescent children with perennial allergic rhinitis. $J$ Allergy Clin Immunol Pract. 2014;2(4):421-427. doi:10.1016/j.jaip.2014.04.008

51. Williams B, Smith WB, Kette FE. Intranasal ciclesonide for allergic rhinitis. J Asthma Allergy. 2008;1:49-54.

52. Skoner DP, Maspero J, Banerji D. Assessment of the long-term safety of inhaled ciclesonide on growth in children with asthma. Pediatrics. 2008;121(1):e1-e14. doi:10.1542/peds.2006-2206

53. Loke YK, Blanco P, Thavarajah M, Wilson AM. Impact of inhaled corticosteroids on growth in children with asthma: systematic review and meta-analysis. PLoS One. 2015;10(7):e0133428. doi:10.1371/ journal.pone.0133428

54. Kelly HW, Sternberg AL, Lescher R, et al. Effect of inhaled glucocorticoids in childhood on adult height. $N$ Engl J Med. 2012;367 (10):904-912. doi:10.1056/NEJMoa1203229

55. de Groot EP, Nijkamp A, Duiverman EJ, Brand PLP. Allergic rhinitis is associated with poor asthma control in children with asthma. Thorax. 2012;67(7):582-587. doi:10.1136/thoraxjnl-2011-201168

56. Allen DB. Influence of inhaled corticosteroids on growth: a pediatric endocrinologist's perspective. Acta Paediatr. 1998;87(2):123-129. doi:10.1111/j.1651-2227.1998.tb00960.x

57. de Benedictis FM, Teper A, Green RJ, Boner AL, Williams L, Medley H. Effects of 2 inhaled corticosteroids on growth: results of a randomized controlled trial. Arch Pediatr Adolesc Med. 2001;155 (11):1248-1254. doi:10.1001/archpedi.155.11.1248

58. Sheth KK, Cook CK, Philpot EE, et al. Concurrent use of intranasal and orally inhaled fluticasone propionate does not affect hypothalamic-pituitary-adrenal-axis function. Allergy Asthma Proc. 2004;25(2):115-120.
59. Pedersen S, O'Byrne P. A comparison of the efficacy and safety of inhaled corticosteroids in asthma. Allergy. 1997;52(39 Suppl):1-34. doi:10.1111/j.1398-9995.1997.tb05047.x

60. Barnes PJ, Pedersen S, Busse WW. Efficacy and safety of inhaled corticosteroids. New developments. Am J Respir Crit Care Med. 1998;157(3 Pt 2):S1-53. doi:10.1164/ajrccm.157.3.157315

61. Administration FaD. Guidance for industry orally inhaled and intranasal corticosteroids: evaluation of the effects on growth in children; March 2007.

62. Allen A, Down G, Newland A, et al. Absolute bioavailability of intranasal fluticasone furoate in healthy subjects. Clin Ther. 2007;29 (7):1415-1420. doi:10.1016/j.clinthera.2007.07.028

63. GlaxoSmithKline. Veramyst prescribing information; 2011.

64. GlaxoSmithKline. Flonase prescribing information; 2019.

65. Merck. Nasonex. Summary of product Characteristics; 2020.

66. Sunovion Pharmaceuticals. Omnaris. Prescribing information; 2013.

67. Sanofi-aventis. Nasacort AQ prescribing information; 2013.

68. Bausch and Lomb. Flunisolide nasal solution. Prescribing information; 2016.

69. AstraZeneca. Rhinocort. Prescribing information; 2010.

70. Sandoz Limited. Budesonide. Summary of product characteristics; 2021.

71. GlaxoSmithKline. Beconase AQ nasal spray. Prescribing information; 2015.

72. Valotis A, Högger P. Human receptor kinetics and lung tissue retention of the enhanced-affinity glucocorticoid fluticasone furoate. Respir Res. 2007;8(1):54. doi:10.1186/1465-9921-8-54

73. Weiswasser M, Zhu J, Chia V, et al. Low systemic bioavailability of ciclesonide aqueous nasal spray and ciclesonide HFA nasal aerosol compared with orally inhaled ciclesonide. J Allergy Clin Immunol. 2008;121(2):S53. doi:10.1016/j.jaci.2007.12.214

\section{Publish your work in this journal}

The Journal of Asthma and Allergy is an international, peer-reviewed open-access journal publishing original research, reports, editorials and commentaries on the following topics: Asthma; Pulmonary physiology; Asthma related clinical health; Clinical immunology and the immunological basis of disease; Pharmacological interventions and new therapies. The manuscript management system is completely online and includes a very quick and fair peer-review system, which is all easy to use. Visit http://www.dovepress.com/testimonials.php to read real quotes from published authors. 